\title{
Early Categorization of Animate/Inanimate Concepts in Young Children with Autism
}

\author{
Cynthia R. Johnson • D. H. Rakison
}

Published online: 4 December 2007

(C) Springer Science + Business Media, LLC 2007

Figures 3 and 4 of "Early Categorization of Animate/Inanimate Concepts in Young Children with Autism" (Volume 18, Number 2, June 2006, pp. 73-89, DOI: 10.1007/s10882-006-9007-7) are incorrect. Please also note that the reference to Fig. 4 in the text on page 81 should have read Fig. 3. The correct figures are as follows:

The online version of the original article can be found at http://dx.doi.org/10.1007/s10882-006-9007-7.

C. R. Johnson $(\bowtie)$

University of Pittsburgh School of Medicine, Children's Hospital of Pittsburgh, Autism Center, 3705 , 5th Avenue, Pittsburg, PA 15213, USA

e-mail: Cynthia.Johnson@chp.edu

D. H. Rakison

Carnegie Mellon University, Pittsburgh, PA, USA 


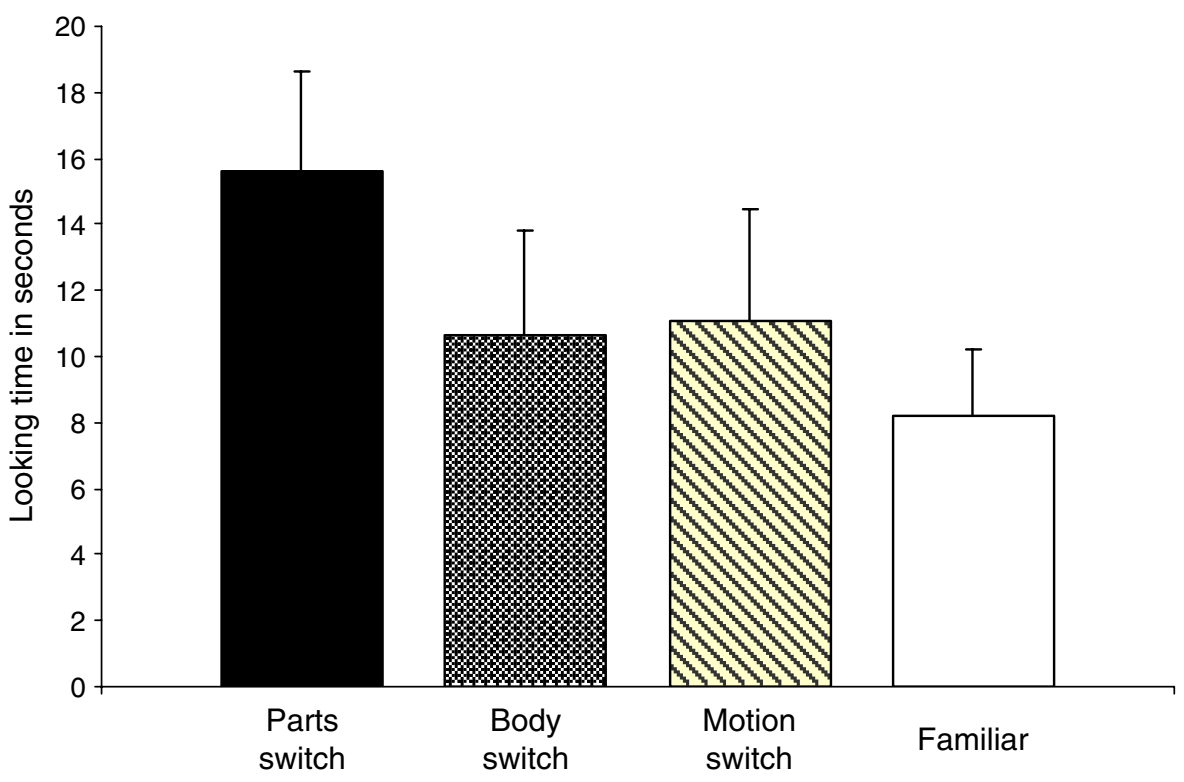

Fig. 3 Looking time to the four test trials in Experiment 1

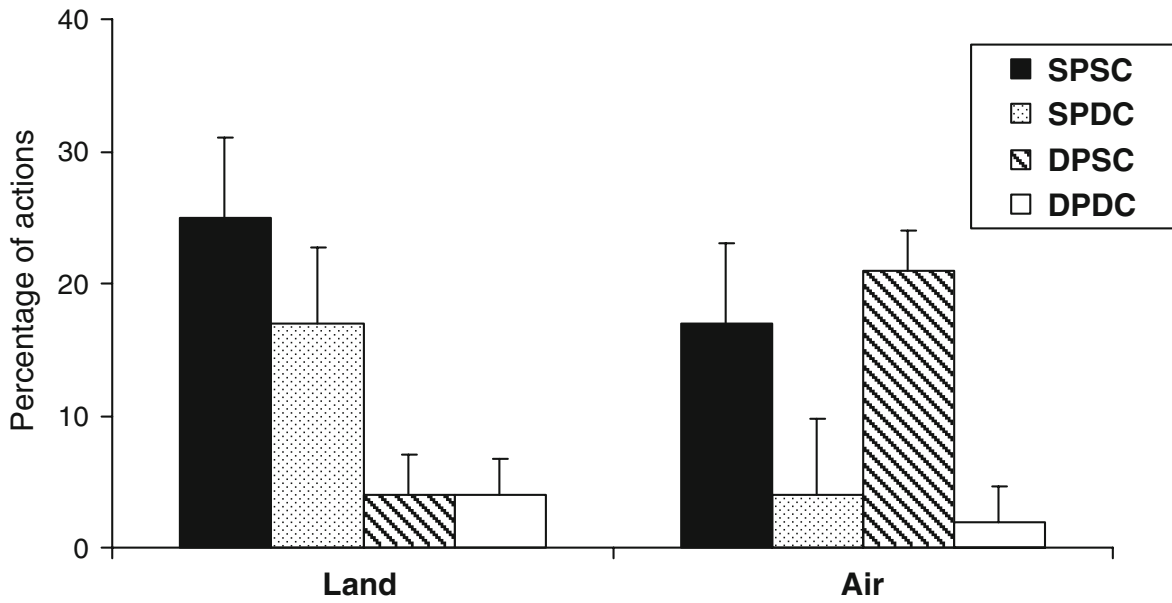

Fig. 4 Land and air motions performed during generalization in Experiment 2 